\title{
The Impact of Mobilization Media on Off-Line and Online Participation: Are Mobilization Effects Medium-Specific?
}

\author{
Sara Vissers', Marc Hooghe ${ }^{2}$, \\ Dietlind Stolle', and Valérie-Anne Mahéo'
}

\begin{abstract}
In recent years, voluntary associations and political organizations have increasingly switched to Internet-based mobilization campaigns, replacing traditional forms of face-to-face recruitment and mobilization. The existing body of empirical research on Internet-based mobilization, however, is not conclusive about the effects this form of mobilization might have. In this article, the authors argue that this lack of strong conclusions might be due to the failure to distinguish different behavioral outcomes of mobilization, and more specifically, a distinction between online and off-line forms of participation is missing. In this experimental study, participants were exposed to potentially mobilizing information either by way of face-to-face interaction or by website. The results of the experiment indicate that web-based mobilization only has a significant effect on online participation, whereas face-to-face mobilization has a significant impact on off-line behavior, which would imply that mobilization effects are medium-specific. The authors close with some observations on what these findings might imply for the democratic consequences of the current trend toward an increasing reliance on Internet-based forms of political mobilization.
\end{abstract}

\section{Keywords}

mobilization, experiments, political participation, online political participation

\section{Introduction}

Mobilization plays a crucial role in explaining participatory behavior. Previous research has shown convincingly that "having been asked" is the single most important determinant of participation (Verba, Schlozman, \& Brady, 1995). Social movement organizations, political parties, and other

'McGill University, Montreal, Quebec, Canada

${ }^{2}$ Catholic University of Leuven, Brussel, Belgium

Corresponding Author:

Marc Hooghe, University of Leuven, Belgium

Email: marc.hooghe@soc.kuleuven.be 
political entrepreneurs therefore spend a considerable effort in attempts to mobilize potential participants. While this process initially might have relied mostly on face-to-face contacts, during the 20th century print and audiovisual media became increasingly important as means to reach out to potential participants. In recent years, the focus has further shifted to web-based forms of communication, as political parties and other political organizations have stepped-up their Internet presence, and they increasingly rely on e-mail or other web-based campaigns to reach out to their audience. From the point of view of the mobilizing agent, the main advantage of the new media is that the marginal cost of an additional contact with a potential participant is almost zero. Sending out an e-mail to 20,000 respondents does not require more resources than sending out an e-mail to 2,000 persons. In that respect, electronic media have a huge advantage over face-to-face, telephone, or print media mobilization tools, where there is, or can be a substantial cost per additional unit being reached. This specific price structure is one of the main forces driving the transition toward webbased forms of mobilization (Bimber, 1998; Krueger, 2006; Ward \& Vedel, 2006).

However, one of the obvious downsides of this new tool is that we do not yet know how effective it is for mobilization. This stands in contrast to what we know about traditional, face-to-face mobilization. Already in 1927, Gosnell demonstrated that face-to-face contacts lead to higher turnout during elections (Jason, Rose, Ferrari, \& Barone, 1984; Kramer, 1970). More recently, a series of field experiments on the impact of mobilization campaigns on voter turnout conducted by Gerber and Green (2000; Green \& Gerber, 2001) confirmed the notion that direct contacts, especially doorto-door canvassing, raise voter turnout.

We know far less, on the other hand, about the mobilizing impact of information and communication technology (ICT)-based communication. Deleting unwanted e-mails is only a matter of seconds. Skeptics would argue that the trash bin is the final destiny for a vast majority of all potentially mobilizing e-mail messages. Indeed, there is by now a long tradition of authors casting doubt on the mobilizing potential of the Internet. In the 1990s, some authors were already expressing their concern about a perceived negative relation between Internet use and civic engagement (Kraut et al., 1998; Margolis \& Resnick, 2000). Overall empirical research has not revealed any clear pattern. Some studies document a clear and significant mobilization effect of Internet communication; others fail to detect any meaningful effects (Jennings \& Zeitner, 2003; Mossberger, Tolbert \& McNeal, 2008; Nickerson, 2007; Weber, Loumakis, \& Bergman, 2003). This lack of clear results might be due to three specific shortcomings in the currently available literature. First, most of the studies are based on cross-sectional survey research, and given the strong self-selective nature of political Internet use, this renders it almost impossible to detect any meaningful causal patterns. Proving causality ideally would require some form of experimental research.

A second cause might be related to a failure to distinguish different types of forms of engagement. There is a lack of appreciation of how specific and ubiquitous cyber activism has become. The available research suggests clearly that cyber activism, in a number of highly relevant aspects, differs substantially from more traditional forms of political participation (Bennett, 2004; Di Gennaro \& Dutton, 2006; Krueger, 2002). Yet, most of the available research on the effects of Internet mobilization just relies on traditional measurements of political participation as a dependent variable. Even in studies on voter turnout, authors hardly make a difference between traditional ways of voting and (electronic) absentee voting (Prevost \& Schaffner, 2008). Nevertheless, medium-specific mobilization effects are plausible. The cross-sectional research by Best and Krueger (2005, p. 196) demonstrates, for example, that online mobilization efforts only had an impact on online forms of participation, without any significant spillover effects to off-line forms of participation.

There are several reasons why mobilization effects might be medium-specific. First of all, there are technical reasons: if one is being exposed to a mobilizing message while using the computer, it usually requires very little additional effort to make an online donation, or to sign an electronic petition. In this case, online participation is literally just a mouse click away. For off-line participation, 
on the other hand, usually further steps are required, and these could function as additional barriers for actual participation (Klandermans \& Oegema, 1987). Second, it has been argued that there are structural differences between online and off-line forms of participation, with regard to the intensity of participation, background characteristics of participants, and the political identities involved (Bennett, 2008; Earl, 2006). Online participation tools allow citizens to connect beyond traditional territorial boundaries and limits (Diani, 2000; Rheingold, 2000). Given the profound differences between online and off-line participation modes, we should allow for the possibility that mobilization dynamics are also different for both forms of participation, an insight that has not yet been taken up in the research literature.

Third, such a dynamic can best be observed in a research design that is able to compare the effectiveness of medium-specific mobilization on various forms of participation in an experimental setup. In this article, then, we try to overcome these shortcomings. First, we rely on a mobilization experiment that should allow us to determine causality in a more controlled environment than in a crosssectional observation. Second, we distinguish in a consistent manner between online and off-line forms of political participation as dependent variables. Furthermore, we link these outcomes to medium-specific mobilization efforts in order to investigate the occurrence of medium-specific mobilization effects. In this case, we would expect that off-line mobilization efforts exclusively or mainly would lead to off-line behavioral consequences, and online efforts to online behavior, but without any transfer taking place between the two modes.

We first briefly review the existing literature on the mobilizing capacity of the Internet, before presenting the specific experimental design. Subsequently, we investigate whether mobilization effects are indeed medium-specific.

\section{The Effect of Medium-Specific Mobilization on Participation}

The effect of Internet on participation behavior has been a salient research topic for some time now (Shah, Schmierbach, Hawkins, Espino, \& Donavan, 2002; Uslaner, 2004). While some authors have argued initially that the time spent on Internet activities would be associated with a decline in engagement levels, research attention rapidly shifted to the question of how new ICTs can contribute to various forms of participation. Web communities allow for the creation and expression of new political identities and particularly more collective identities (Brunsting \& Postmes, 2002). Internet is also instrumental in creating international forms of activism, and it has been argued that the recent rise in transnational activism would have been completely impossible without the presence of the Internet and e-mail (Laer, 2010; Van Aelst \& Walgrave, 2002). Social movement organizations and political parties have also increasingly come to use new communication media as a mobilization tool. For political parties, party websites have become one of the most important tools to reach out to potential voters (Gibson \& Ward, 2009; Ward, Owen, Davis, \& Taras, 2008). Telephone messages, e-mails, and even text messaging are now increasingly being used as means to convince potential voters (Dale \& Strauss, 2009).

The existing body of literature on the effects of Internet-based mobilization, however, is far from conclusive, with wildly different research outcomes. On one hand, there are studies suggesting that Internet use has no or only a very limited impact on political participation. Bimber $(2001,2003)$ is one of the first authors who examined the relation between seeking political information online and involvement in different political activities, employing survey data gathered during the 1996, 1998, and 2000 election campaigns in the United States. The analysis suggests that most relations were not significant, with a few minor exceptions. Furthermore, effects did not prove to be stable across the three election campaigns that were studied. Bimber concludes therefore that "the new information environment has not changed levels of political engagement in any substantial way" (Bimber, 2003, p. 224). In a similar design, Tolbert and McNeal (2003) showed that in two out of the three electoral 
campaigns they monitored, there was a significant relation between political Internet use but not in the third campaign. Jennings and Zeitner (2003) used a quasi-experimental longitudinal design to disentangle the consequences of Internet access and Internet use to follow public affairs on political and civic engagement. Their multivariate analysis revealed only a very small independent impact of the Internet.

Some other studies show a stronger positive relation between Internet-based political information and political participation. Johnson and Kaye (2003) recruited the participants in their web survey among users of political websites, and they found a positive relation between political Internet use and political engagement. Results of a self-selective online survey among visitors of the National Geographic website revealed a positive relation between Internet involvement and political participation. Respondents who are highly engaged in online life are more inclined to participate in political life (Weber et al., 2003). Quintelier and Vissers (2008) employ a representative youth survey among 16-year-olds in Belgium, indicating a positive relation between various activities performed online and the propensity to participate in political life. None of these studies made a distinction between online and off-line participation activities. However, in order to disentangle the mobilization impact of the distinct features of the Internet and political participation patterns, it is important to make the differentiation between these medium-specific participation types.

Other studies do make an empirical distinction between online and off-line participation (Brunsting \& Postmes, 2002). Based on a web survey among Dutch youth, De Vreese (2007) explored the relationship between different types of Internet mobilization and online political participation. The results revealed a statistically significant positive relation between online mobilization and online political participation. Gibson, Lusoli, and Ward (2005) explored the relation between Internet use and online and off-line political participation among U.K. citizens in 2002. The authors found that receiving e-stimuli significantly enhanced the propensity to become politically engaged in the online world, controlling for political interest and previous political engagement. However, the impact of online mobilization tools remained limited to online forms of political participation and did not spillover to off-line participation. Of course, several studies explore how Internet mobilization can contribute to the organization and character of street protests and find an important role for Internet-based mobilization (Bennett, Breuning \& Givens, 2008; see also Fisher \& Boekkooi, 2010), but this research usually does not directly compare the benefits of Internet mobilization for both online and off-line participation. In short, studies that distinguish between online and off-line participation seem to find that Internet mobilization mostly affects online forms of participation.

Very few studies compare different mobilization media and their media-specific effects. The analysis by Best and Krueger (2005) based on U.S. data shows that Internet-based mobilization significantly increases online participation, compared to conventional off-line mobilization, controlling for SES, Internet access, connection speed, Internet and civic skills, free time, and the level of political interest. The results, however, did not reveal any significant effect of conventional mobilization on off-line participation. Overall, their findings suggest that mobilization media have different effects on different forms of participation. Conventional off-line mobilization mainly stimulates off-line participation activities, whereas Internet-based mobilization (with the exception of street protests) mainly fosters online participation. To conclude, previous studies seem to be in line with the idea that mobilization is more effective in stimulating medium-specific participation.

However, a major limitation of most of the existing studies is that they are based on crosssectional data, which are not able to demonstrate causality. For the Best and Krueger (2005) study, too, the authors rely on a reported measure of exposure to online and off-line mobilization efforts. Yet, it is very likely that subsequent participation acts might affect the propensity to remember the mobilization experience and thus disproportionately influence the indicated online mobilization experience. A respondent who just deleted the mobilizing e-mail message might not remember this very short experience at all, while another respondent who went on to read the message and, for 
example, to sign a petition is far more likely to remember this event. While both types of respondents might have been mobilized by online efforts; this difference will not show up in the measure of online mobilization exposure. As such, this phenomenon of selective memories might endanger the validity of the Best and Krueger (2005) findings. The problem of differential memory of mobilization efforts is distinct, but in addition, any positive relation between political Internet use and political involvement could simply be the result of preexisting levels of civic engagement. According to Jennings and Zeitner (2003), active individuals have incorporated the Internet in their political participation repertoires, but to them it does not show any independent effect of the Internet itself.

Experimental designs could offer a solution to this causal puzzle, and we do have access to some studies relying on various experiments on the mobilizing impact of Internet. Nickerson (2007) found that the use of mass e-mail messages is an ineffective tool to mobilize voters. This study demonstrated those who received mobilizing e-mails were not more likely to go out and vote than those who did not. The question, however, is to what extent this finding on voting can be generalized toward other forms of political participation. Again, while Internet voting might be more easily enhanced by e-mail messages, this is not necessarily the case for off-line voting. Applying the logic developed earlier would mean that online forms of participation could be mobilized in a different manner than off-line forms of participation. In short, the literature needs a more thorough experimental test of comparing the mobilizational power of Internet-based and other conventional media (e.g., face-to-face) on differentiated (media-specific) forms of participation.

Before proceeding to stating the hypotheses, one more caveat needs to be discussed. One of the main elements responsible for the differential impact on online and off-line forms of participation is the role of Internet skills. The concept refers to the ability of Internet users to locate content online effectively and efficiently (Hargittai, 2004). Various authors suggest that Internet use is largely driven by the user's online skills (Hargittai \& Hinnant, 2008; Mossberger, Tolbert \& Stansbury, 2003; Van Dijk, 2005). While Internet skills are necessary to engage in online activism, they self-evidently do not play a role in off-line forms of activism. It is crucial, therefore, to control for the presence of Internet skills among potential participants. Krueger (2002), for example, shows the importance of taking Internet skills into account when predicting online participation. Moreover, Internet skills tend to be more important to predict citizens' online political behavior than the traditional civic skills emphasized in the civic resource model of Verba, Schlozman, and Brady (1995). In the current experimental research project, therefore, Internet skills will function as a major control variable.

The literature therefore allows us to formulate our hypothesis:

Web and conventional face-to-face mobilization are medium-specific.

More specifically:

Hypothesis 1: Internet-based mobilization efforts lead mostly to effects on online participation. Hypothesis 2: Face-to-face mobilization efforts lead mostly to effects on off-line participation.

We should note that we expect the effect of Internet-based mobilization on online forms of political participation to be strongly dependent on preexisting levels of Internet skills.

\section{Experimental Design}

In order to detect the effects of various mobilization experiences, we conducted randomized experiments with pretest and delayed posttest measurements. Participants were exposed either to face-toface or to Internet-based mobilizing information. The topic chosen for mobilization was greenhouse warming, and the experiments were conducted by a fictitious environmental organization. We set up 
Table I. Background Variable Participants

\begin{tabular}{|c|c|c|c|c|c|c|}
\hline & & $n$ & & $n$ & & $n$ \\
\hline Gender (female) & $53.2 \%$ & 109 & & & & \\
\hline Education parents & Mother & 100 & Father & 100 & & \\
\hline Less than high school diploma & $37.0 \%$ & & $34.4 \%$ & & & \\
\hline Trade or vocational diploma & $24.0 \%$ & & $26.3 \%$ & & & \\
\hline High school diploma & $15.0 \%$ & & $12.1 \%$ & & & \\
\hline Higher education & $13.0 \%$ & & $16.2 \%$ & & & \\
\hline Not sure & $11.0 \%$ & & $11.1 \%$ & & & \\
\hline Religion & & 109 & & & & \\
\hline Catholic & $35.8 \%$ & & & & & \\
\hline Islamic & $9.2 \%$ & & & & & \\
\hline Orthodox & $2.8 \%$ & & & & & \\
\hline No religion & $43.1 \%$ & & & & & \\
\hline Average age & $20.4(2.19)$ & & & & & \\
\hline Political interest & & 109 & & & & \\
\hline Very interested & $5.5 \%$ & & & & & \\
\hline Quite interested & $33.9 \%$ & & & & & \\
\hline Hardly interested & $37.9 \%$ & & & & & \\
\hline Not at all interested & $22.9 \%$ & & & & & \\
\hline $\begin{array}{l}\text { Media use politics and current } \\
\text { affairs (On average weekday) }\end{array}$ & TV & 109 & Newspaper & 109 & Internet & 108 \\
\hline Never & $6.4 \%$ & & & & & \\
\hline Once in a while & $46.8 \%$ & & & & & \\
\hline Fairly often & $45.0 \%$ & & & & & \\
\hline All the time & $1.8 \%$ & & & & & \\
\hline $\begin{array}{l}\text { Average off-line environmental } \\
\text { participation, } 0-13 \text { (pretest) }\end{array}$ & $5.87(2.65)$ & 100 & & & & \\
\hline $\begin{array}{l}\text { Average online environmental } \\
\text { participation, } 0-6 \text { (pretest) }\end{array}$ & I.3। (I.53) & 108 & & & & \\
\hline
\end{tabular}

Note. Entries are percentages or average with standard deviation within parentheses.

a fictitious organization, in order to avoid that any preexisting judgment on one of the better known environmental nongovernmental organizations (NGOs) would have an effect on the mobilization outcome. Participants were invited into the university premises, on behalf of the organization.

\section{Participants}

The participants were based in Belgium, a country that can be considered as rather typical for Internet access and environmental consciousness in Western Europe (Eurobarometer, 2008; Jowell \& the Central Co-ordinating Team, 2005). Recently, critique has been voiced about the tendency to rely almost exclusively on student participants in experimental research, as it is taken that this onesided recruitment might endanger the capacity to generalize from the results of experimental research (Hooghe, Stolle, Mahéo, \& Vissers, 2010; Kam, Wilking, \& Zechmeister, 2007). This seems to be especially the case for this study, since we can safely assume that university students will have much higher scores on Internet skills than most of the population, thus potentially enhancing the mobilization power of the Internet on online participation. Similarly, among university students one can expect less variation on Internet skills. It is an important contribution of this study to sample participants from disadvantaged education and socioeconomic backgrounds. These participants were sampled using a network of professional training services (see Table 1 for an overview of 
the participants' background characteristics). The results in Table 1 indicate that when comparing to Belgian statistics of Belgian youth participants' parents tend to be less formally educated. More than half of the participants' mother and/or father received less than a high school diploma or a trade or vocational diploma compared to $15 \%$ in the Belgian youth data (Hooghe, Quintelier, Claes, \& Dejaeghere, 2009). Participants also report lower levels of political interest and political engagement than the average Belgian youth. This suggests that - as intended-the participants come from a lower socioeconomic background and are less interested and engaged in politics, compared to their higher formally educated peers.

In total, 109 participants took part in the experimental condition, all of them aged between 18 and 25 . During recruitment, respondents were given the opportunity to voluntarily participate in a threestep research project, starting with the administration of a pretest survey (Wave 1), followed by the participation in an activity (mobilizational manipulation) around 10 days after the pretest (Wave 2), and ending with a delayed postal survey scheduled 3 months after the mobilization manipulation (Wave 3).

\section{Experimental Manipulations}

In the experiments, all participants received the same mobilization information but using different technologies to get the information across. Therefore, we can assume that any differences we might observe in the outcome of the mobilization process are the result of the technologies being used (Miller \& Reese, 1982). Two different face-to-face and two web mobilization tools were developed while we also constructed a control group, with participants randomly assigned to one of these conditions. During recruitment, participants were asked to sign up for an activity appointment (without revealing any information about the experimental conditions). The fact that participants chose appointments for activities according to their preferred date and time of availability (and not based on the type of activities, which were unknown to the participants) helped to ensure that they were randomly assigned to experimental conditions. For the assignments of the participants to the different conditions, we had to take into account the time and date that the subjects were available to take part in the experimental sessions. We are aware of the fact that this randomization procedure is less conventional than the traditional randomization strategies employing tables with random numbers or random number generators. The ultimate test for successful randomization, however, is to verify that there are no substantial differences between the groups participating in the different experimental conditions (which will be discussed in the analyses sections).

The content of the test conditions was identical, with narrowly targeted information on the consequences of human behavior for climate change, and the effects behavioral change might have. The mobilization information was designed to foster behavioral outcomes, both collectively (political action) and individually (behavioral change). We tested two simple, traditional and widely used mobilization tools, that is, a presentation by a speaker (the face-to-face noninteractive condition) and a directed role game (the face-to-face interactive condition). In the face-to-face noninteractive condition, a professional speaker was introduced as a team member of the fictitious organization giving a presentation with PowerPoint slides. In the face-to-face interactive condition, the same speaker was again introduced as a member of the organization, and he or she directed an interactive role game in which the participants were required to take part. This game required participants, by groups of two to three, to take on a role from a list of six actors: an industrial lobby group, a Green political party, a students' group, citizens from the Tuvalu Islands, an environmental NGO, and a political party opposing governmental action to stop global warming. Participants were provided with all the necessary information about the position of this actor on global warming and this information was used in a mock jury meeting. 
Table 2. Participants in the Experiment

\begin{tabular}{lcr}
\hline Condition & $n$ & \\
\hline Noninteractive website & 12 & 43 \\
Interactive website & 31 & 45 \\
Conference & 19 & \\
Role-play & 26 & 21 \\
Control group & 21 & 109 \\
Total & 109 & \\
\hline
\end{tabular}

Note. Sample sizes refer to the participants who were involved in all three waves of the study.

Two other test conditions were based on Internet communication, and here too we introduced a distinction between interactive and noninteractive mobilization. In these conditions, participants were seated at individual computer stations and were asked to browse the organization's website. This website was especially constructed for the experiment, and it was only accessible by the participants. The website was either noninteractive, providing the same information as the face-to-face speaking, or interactive, including a forum where questions could be asked and reacted to.

For their part, the control group participants were shown two episodes of a television cartoon series, that is, The Simpsons, which had no mobilization potential and had nothing to do with political issues or global warming.

\section{Recruitment}

The experiments were conducted over a period of 4 months. In practice, participants were first recruited and given an opportunity to fill in a short prequestionnaire (15-30 min) about general opinions on society, political attitudes and behaviors, and about global warming knowledge and participation (Wave 1). They were subsequently asked to sign up for an activity appointment, 10 days later, from a selection of dates and times. The research team randomly set a different experimental condition for each activity session. Participants took part in groups to only one of the experiments, which lasted for 30-45 min. Subsequently, they were asked to fill in a short postquestionnaire (10$20 \mathrm{~min}$ ). Approximately 3 months later, participants were sent a last delayed posttest by mail, and $61.3 \%$ of all participants responded to this third wave of the study. This attrition did not pose any problem for the validity of the results, since there were no significant differences in pretest scores between those who remained in the sample during the full three waves and the dropouts among the different experimental conditions. In sum, 43 participants were exposed to Internet information; 45 to face-to-face information; and 21 participants formed a control group (Table 2).

\section{Dependent Variables}

The main goal of this experiment is to determine whether the mobilization medium (Internet versus face-to-face) has medium-specific consequences (on online and off-line participation). The experiments and mobilization content was thus designed to stimulate off-line and online participation. The measures of participatory behavior were taken a few weeks before the experimental manipulation (Wave 1) and 3 months following the experimental manipulation (Wave 3). We did not measure political behavior immediately following the experimental exposure (Wave 2), because participants (who had not yet left the building) did not yet have the chance to behave in a more environmentally friendly manner.

Furthermore, in order to obtain a comparable set of online and off-line forms of participation, individualized political acts were chosen that could have been performed by the participants 
themselves in an individualized manner, however, they do not exclude a logic of collective action (Micheletti, 2003). In the literature, these forms of participation have been dubbed individualized collective action (Micheletti, 2003).

In the pretest, we measured participation in the past 12 months; whereas in the delayed posttest we measured participation in the past 3 months. This period of 3 months was selected, since the interest is in the level of activity in the 3 months following the experiment.

\section{Off-Line Participation}

In order to measure the impact of the different mobilization tools on off-line participation, we included individual measures of environmental participation, for example, in order to reduce greenhouse gas emissions included taking public transportation more often, cut down on meat consumption, and reducing electricity usage (see Appendix for the exact question wording and descriptives of the used variables). Both Wave 1 and Wave 3 off-line participation scales are additive scales, based on 13 different activities. Both in Wave 1 (Cronbach's $\alpha=.658$ ) and in Wave 3 the participation scale proved to be one-dimensional (Cronbach's $\alpha=.773$ ).

\section{Online Participation}

In order to measure the mobilization potential of the different mobilization tools on online participation, we used a battery of specific online participation activities. Also here we asked respondents whether they had participated in specific forms of online political action, for example, sent an e-card/article from a social, political, or environmental organization to a friend or colleague; recommended the website or the hyperlink of a social, political, or environmental organization; signed up for an e-mail newsletter of an organization (see Appendix for the exact question wording and descriptives of the used variables). The online participation scale is an additive scale with a Cronbach's $\alpha$ of .685 in Wave 1 and .769 in Wave 3 of the experiment.

\section{Internet Skills}

As we already indicated, Internet skills proved to be an important predictor for online participation in previous research. In order to measure participants' level of Internet skills, we asked the respondents how often they had performed the following activities in the past 12 months: used a search engine to find information; sent e-mails; posted messages in chat rooms, newsgroups, blogs, or online forums, played interactive games, phoned via the Internet, peer-to peer file sharing to exchange movies, music, and so on; made a webpage or created a blog; and finally bought or purchased things online. The Internet skills scale (range 8-24 points) proved to be internally coherent with a Cronbach's $\alpha$ of .699, a mean of 15.23 and standard deviation of 3.35.

\section{Method}

Hierarchical ordinary least squares (OLS) regression was chosen as the main technique for testing our hypotheses in a pretest-posttest design. This estimation technique has the advantage to improve regression estimates by adding an extra regression to an ordinary regression model. Hence this procedure allows to test the significance of added variables to the explanation of the model reflected in the $R^{2}$ (Cohen et al., 2006). We use this analysis technique to examine the effects of the experimental conditions, while controlling for pretest values of past participation and the participants' level of Internet skills. Hierarchical regression allows us to examine the relative impact of the treatment conditions, based on how much they add to the prediction of the dependent variable above the explained variance accounted for by the pretest scores. The employment of pretest scores allows us to compare 


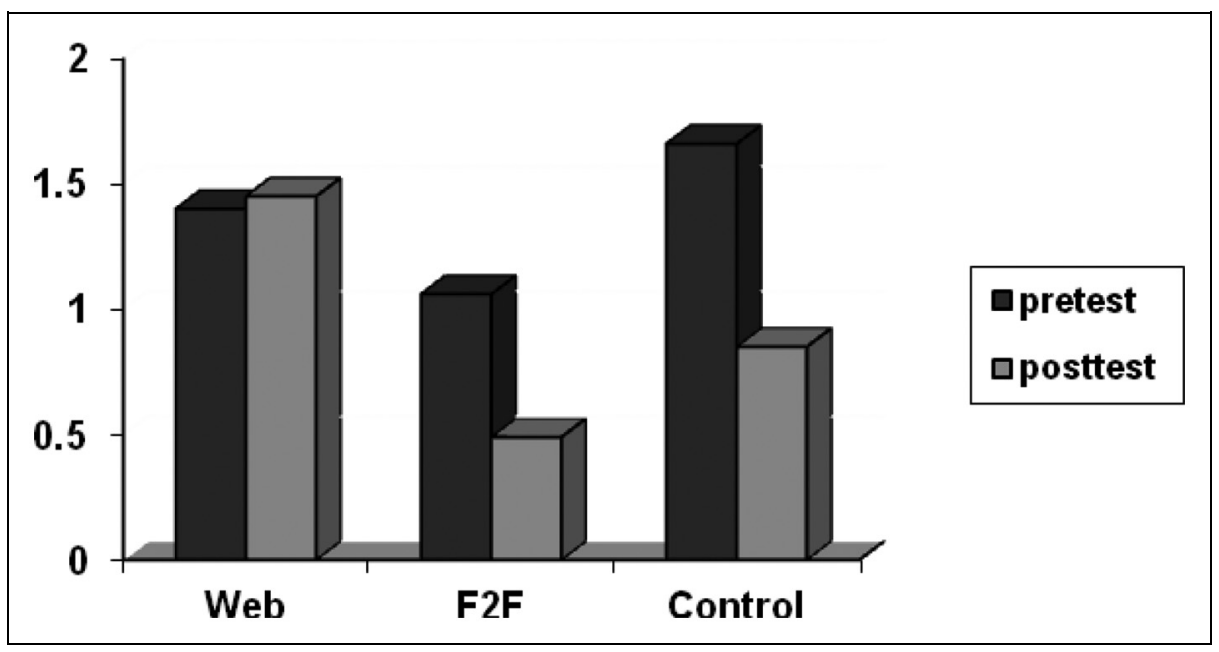

Figure I. Mean changes in online participation. Note: Online participation (pretest and posttest) for three experimental conditions. Dependent variable: additive scale of six online participation acts. $n=106$. Pretest online participation was measured during the past 12 months. Posttest online participation was measured during the past 3 months.

the web, face-to-face, and brochure conditions with the control group on posttest scores, while holding pretest scores constant. The main purpose of using these pretest control variables is to adjust the posttest scores for any remaining differences, which reduces the unexplained variance in the dependent variable, and consequently allow for a more efficient estimation of the experimental effects (Cohen, Cohen, West, \& Aiken, 2003; Gelman \& Hill, 2007).

As we are here particularly interested in the comparison between Internet and face-to-face mobilization, we limit the analyses to these conditions. The web condition collapses the interactive and the noninteractive web stimuli, and the face-to-face condition collapses the noninteractive conference and the interactive role-play. Because we have three experimental conditions, we present the conditions with two dummy coded variables in the model. The control group serves as the reference category.

\section{Results}

\section{Pretreatment Outcomes}

No significant differences appeared in the pretreatment outcome measures for online participation, $F(2,105)=1.231$ n.s., and off-line participation, $F(2,97)=0.407$ n.s., between the three experimental conditions, that is, the web, the face-to-face condition, and the control group. In addition, we did not encounter significant differences in Internet skills between participants in the experimental conditions, $F(2,106)=0.123$ n.s.

\section{Online Participation}

Figure 1 shows the mean changes in online participation before and after the mobilization for the two mobilization media and the control group. As was already mentioned, initial online participation was measured in the pretest where we used a time frame during the past 12 months. Participation after the mobilization experiment was measured within a time frame of the past 3 months. Given the different time frames, average participation levels are lower in Wave 3 than in Wave 1 for the simple reason 
Table 3. Mobilization Effects on Online Environmental Participation

\begin{tabular}{lcccc}
\hline & $b$ & $S E b$ & $\beta$ & Significance \\
\hline Step I & & & & .024 \\
$\quad$ Constant & 0.405 & 0.176 & .000 \\
$\quad$ Initial online participation & 0.416 & 0.089 & .418 & .628 \\
Step 2 & & & .000 \\
$\quad$ Constant & 0.161 & 0.331 & .407 & .033 \\
Initial online participation & 0.406 & 0.086 & .254 & .773 \\
Web & 0.783 & 0.363 & -.034 & .866 \\
Face-to-face & -0.104 & 0.360 & & .000 \\
Step 3 & & & .402 & .048 \\
Constant & -0.105 & 0.624 & .241 & .712 \\
Initial online participation & 0.400 & 0.087 & -.045 & .616 \\
Web & 0.744 & 0.372 & .045 & .175 for Step \\
Face-to-face & -0.136 & 0.367 & 0.039 & \\
Internet skills & 0.020 & & & \\
\hline
\end{tabular}

Notes. Entries are the result of a hierarchical ordinary least squares (OLS) regression analysis. $n=106 ; R^{2}=.175$ for Step I; $\Delta R^{2}=.077^{* *}$ for Step 2; $\Delta R^{2}=.002$ (n.s.) for Step 3. Significance: $* * * p<.001$. $*^{*} p<.01$. $*_{p}<.05$.

that in a period of 12 months individuals have more time and possibilities to participate compared to a period of 3 months. However, given the fact that this was a constant for all groups, the data can still be used to compare groups. Figure 1 already suggests that Internet mobilization was most successful in stimulating online participation in the 3 months following the experimental condition.

Table 3 presents the results of the hierarchical OLS regression measuring the effect of the two mobilization conditions (compared to the control group) on online participation, while controlling for online participation prior to the experimental treatment and level of Internet skills. The first step of the analysis, where we test the relation between prior participation and participation after mobilization, reveals a positive significant effect of prior participation. This indicates that individuals with higher previous levels of engagement are also more likely to continue this behavior following the experiment. In the second step, we entered the main effects of face-to-face and Internet mobilization, compared to the control group. The results confirm the first insights from Figure 1. Only Internet mobilization had a statistically significant effect $(\beta=.25)$ on online participation, compared to the control group. The face-to-face condition did not have an effect on online participation

In Step 3 of the analysis, we enter Internet skills as a control variable. These skills, however, did not have an effect on the participation level in Wave 3 of the study. We also tested for the interaction effect of Internet skills with the experimental conditions. The results, however, did not reveal any statistically significant effect. In other words, the level of Internet skills is no significant predictor for the increase in online participation, nor does it have a significant impact on the mobilization effect of Internet mobilization.

The conclusion thus far is that controlling for initial online participation and Internet skills, only web mobilization was effective in stimulating online participation, confirming Hypothesis 1 . However, Internet skills did not have the expected effects.

\section{Off-Line Participation}

Similar to online participation, we measured off-line participation both during the first wave as in Wave 3, 3 months following the experimental condition.

Figure 2 reports the mean changes in off-line participation before and after the mobilization experiment. The participation level of the control group remains constant, but we observe a rise for 


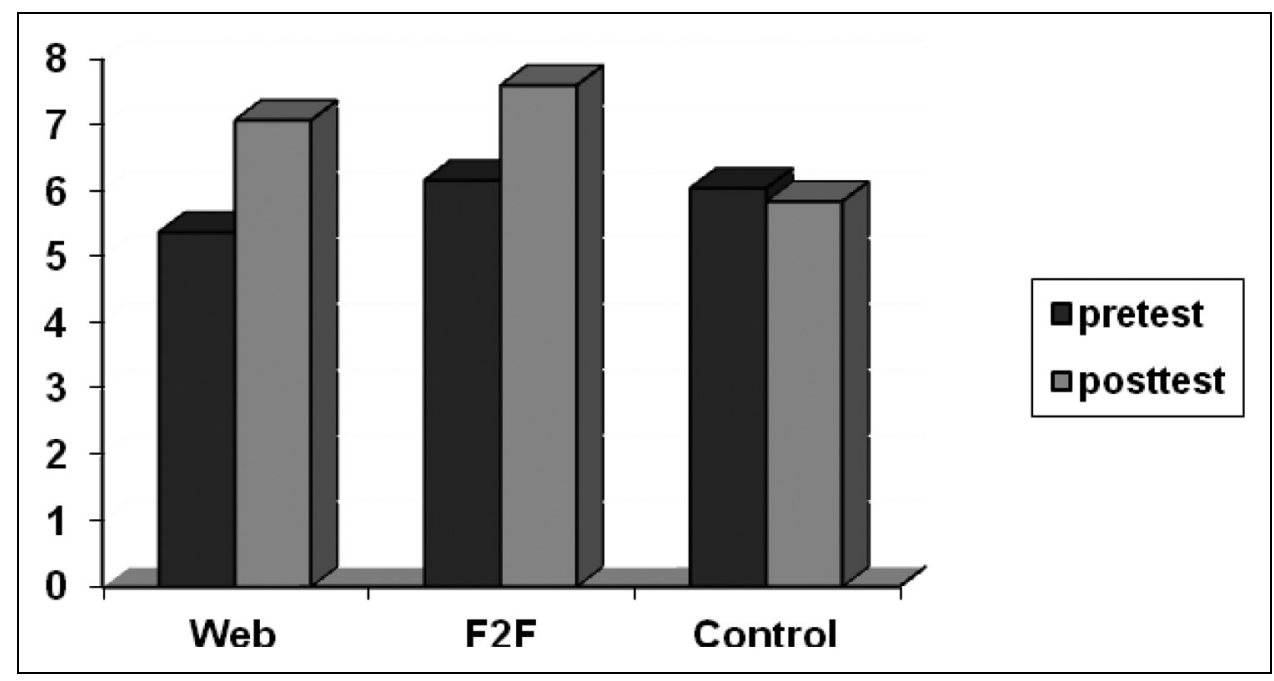

Figure 2. Mean changes in off-line participation. Note: Off-line participation (pretest and posttest) for three experimental conditions. $n=98$. Dependent variable: cumulative scale of 13 participation acts. Pretest off-line participation was measured during the past 12 months. Posttest off-line participation was measured during the past 3 months.

Table 4. Mobilization Effects on Off-Line Environmental Participation

\begin{tabular}{lcccc}
\hline & $b$ & $S E b$ & $\beta$ & Significance \\
\hline Step I & & & & \\
$\quad$ Constant & 10.69 & 0.61 & & .000 \\
$\quad$ Initial off-line participation & -0.62 & 0.09 & -.56 & .000 \\
Step 2 & & & & .000 \\
$\quad$ Constant & 9.71 & 0.77 & -.57 & .000 \\
Initial off-line participation & -0.64 & 0.09 & .13 & .228 \\
Web & 0.80 & 0.66 & .31 & .006 \\
Face-to-face & 1.84 & 0.65 & & .000 \\
Step 3 & & & .000 \\
Constant & 9.23 & 1.29 & -.57 & .279 \\
Initial off-line participation & -0.64 & 0.09 & .12 & .007 \\
Web & 0.74 & 0.68 & .04 & .643 \\
Face-to-face & 1.81 & 0.65 & 0.08 & \\
Internet skills & 0.04 & & & \\
\hline
\end{tabular}

Notes. Entries are the result of a hierarchical ordinary least squares (OLS) regression analysis. $n=98 ; R^{2}=.312$ for Step I; $\Delta R^{2}=.059 *$ for Step $2 ; \Delta R^{2}=.001$ (n.s.) for Step 3. Significance: $* * * p<.001$. $*_{*} * 0.01$. $* p<.05$.

the two experimental conditions. For the analysis of off-line participation, we employed exactly the same method as for online participation (Table 4). In Step 1, we controlled for initial participation. Here we see that contrary to online participation, we encounter a negative effect of initial off-line activity $(\beta=-.56)$. This suggests that the mobilization experience was most effective for the participants that initially had low engagement levels. In Step 2, we include the main effects of the two mobilization conditions, compared to the control group. The explained variance of the model significantly increased with 0.059 points. The results show a significant and strong effect of face-to-face mobilization, but there is no effect of Internet-based mobilization exposure. Despite the rise of 
postexperimental off-line participation for both the web mobilization group and the face-to-face mobilization group in Figure 2, controlling for pretest participation in the multivariate analysis suggests that web mobilization has no significant effect on off-line participation in the medium run. ${ }^{1}$ To conclude, similar to online participation, multivariate analysis suggests a medium-specific mobilization effect from face-to-face mobilization to off-line participation. However, the distribution of the data limits our ability to completely exclude that web-based mobilization also influences offline participation. With the limitations mentioned, our analysis here suggests that this is not the case. In the final step of the analysis, we included Internet skills. Also here the analysis could not reveal a significant effect of Internet skills.

\section{Discussion}

Results of this experimental design confirm the notion that the effects of mobilization media tend to be medium-specific. That is web mobilization leads to increased online participation, whereas faceto-face mobilization leads to increased off-line participation. At the same time, face-to-face mobilization does not affect online participation, and our analysis also suggests that web mobilization did not shape off-line participation. There seems to be no spillover effects at work. As such, our experiment confirms the finding of medium-specific mobilization effects that was already present in the work of Best and Krueger (2005), but now in a controlled experimental condition. The main advantage of this setting is that we exclude the possibility of self-selection: participants were randomly assigned to one of the experimental conditions, and the analysis demonstrated that there were no significant differences in the level of the theoretically relevant variables between the three experimental groups (Internet, face-to-face, and control group).

The lack of spillover effects is an important finding since we know that social movement organizations increasingly rely on Internet-based mobilization tools. Within the scientific community, however, there is not yet a consensus on how the effectiveness of these new mobilizing tools could be measured. It is clear that a standard approach where only off-line participation is measured merely reveals part of the story. While Internet mobilization boosts Internet-based forms of participation, it does not boost off-line participation. Thus, an increased reliance on Internet-based forms of mobilization entails the risk that it simply strengthens the cycle of specific online forms of participation; but does do little to change off-line behavior. To some, this might be a worrying finding, since online forms of participation are usually perceived to be less powerful, fleeting, and unsustainable. One argument is that political decision makers might not pay attention to messages received over the Internet. However, more research needs to determine whether such worries are justified. In our scenario here, we would estimate that the off-line forms of behavior would have more powerful repercussions to actually affect the emission of greenhouse gases, however even the effect of such off-line environmental behavior is doubted in some academic circles (Herring, 2006; Pearce, 1998). So much is to be seen which types of political participation are more useful.

We assumed that the preexisting level of Internet skills would have an effect on the mobilization potential of Internet-based mobilization tools. This, however, was not the case. Apparently, Internet skills (or at least a minimum level of Internet skills) are now so generally spread among young age groups within Western countries that it seems that skills do no longer shape participation levels. In future research, this effect should be investigated on a general, adult sample, where we assume more variance in the occurrence of Internet skills.

The main problem with any effort to generalize these findings self-evidently is that they are the result of a controlled laboratory experiment. Participants were randomly exposed to this information, whether they preferred this to happen or not. These are not real-life conditions where actors more frequently self-select into different types of mobilization exposure. In addition, in reality, political and social mobilization is rarely random, as political actors tend to focus on specific target 
groups who are most likely to positively respond. The advantage of this approach is that it allowed us to simulate a situation where mobilization is not selective and where there is little recruitment bias. The downside of this approach, however, is that we could not capture the individuals' decision not to respond to the mobilization efforts. In real life, citizens can decide not to respond to door-to-door canvassing efforts, not to read leaflets, brochures, mobilizing e-mails, and so on. The lab experiments induced a rather artificial situation where all participants were more or less "forced" to pay attention to the mobilization message. Respondents were not allowed to leave the website and surf to other websites. In reality, mobilization might be completely different in this regard. Even so, for young people we might expect that this effect is randomly distributed across all experimental groups and thus should not influence the gist of our results on the importance of medium-specific mobilization effects on online and off-line participation.

\section{Appendix: Variables Used in the Analysis Question Wording}

\section{Off-Line Participation}

- The Wave 1 questionnaire included behavior in the past 12 months: "In the past 12 months, did you personally do any of the following things, in order to reduce the general emissions of polluting gases (i.e., $\mathrm{CO}_{2}$ ), or to help stop global warming?"

- The Wave 3 questionnaire included measured behavior in the period since the experiment: "In the last 3 months, did you personally do any of the following things, in order to reduce the general emissions of polluting gases (i.e., $\mathrm{CO}_{2}$ ), or to help stop global warming?"

List of actions:

- Took public transportation more often

- Read more information on the issue of global warming, in brochures or magazines

- Walked or bicycled for short distances

- Tried to use less electricity

- Cut down on meat consumption

- Turned down the heating temperature in the house in general

- Gave information on global warming to family/friends/colleagues

- Took showers instead of a bath and/or reduced your time in the shower

- Bought more local products (even if they are sometimes more expensive)

- Turned off all "machines" when you did not use them

- Reduced your consumption of paper and reused paper

- Recycled

- Reduced heating at night and when you leave your house

\section{Online Participation}

- The questionnaire of Wave 1 measured online participation in the past 12 months: There are different ways of trying to improve things in Belgium or to help prevent things from going wrong. During the last 12 months, have you done any of the following political activities?

- The questionnaire of Wave 3 measured online participation since the experiment: There are different ways of trying to improve things in Belgium or to help prevent things from going wrong. During the last 3 months, have you done any of the following political activities? 


\section{List of actions:}

- Sent an e-card/joke/article from an online political/social or environmental organization or newspaper to a friend/colleague/acquaintance/listserv

- Visited a website of a political/social or environmental organization/NGO

- Recommended a political/social or environmental organization's website or a campaign hyperlink to a friend/colleague/acquaintance/listserv

- Signed up for an e-mail newsletter (e-bulletin) from a political/social or environmental organization

- Sent an e-mail to a political/social or environmental organization

- Posted a message with political content in a forum/chat room or blog

\section{Internet Skills}

You can do different activities when you are online. During the last 12 months, have you done any of the following activities? [Never, From time to time, Often]

List of activities:

- Used a search engine to find information

- Sent e-mails

- Posted messages in chat rooms, newsgroups, blogs, or in online forums

- Played interactive games

- Phoned via the Internet

- Peer-to-peer file sharing to exchange movies, music, etc.

- Made a webpage or create a blog

- Bought or purchased things online

Table A I. Descriptives of Off-Line Participation, Online Participation, and Internet skills

\begin{tabular}{lcccc}
\hline & Mean & SD & Cronbach's $\alpha$ & $n$ \\
\hline Off-line participation pretest & 5.98 & 2.782 & .746 & 100 \\
Off-line participation delayed posttest & 7.68 & 3.125 & .780 & 107 \\
Online participation pretest & 1.31 & 1.536 & .685 & 108 \\
Online participation delayed posttest & 0.93 & 1.506 & .769 & 107 \\
Internet skills pretest & 15.23 & 3.349 & .699 & 109 \\
\hline
\end{tabular}

\section{Declaration of Conflicting Interests}

The author(s) declared no conflicts of interest with respect to the authorship and/or publication of this article.

\section{Funding}

The author(s) received no financial support for the research and/or authorship of this article.

\section{Note}

1. This is mainly due to the fact that participants in the web condition were more scattered around the extremes of the pretest participation scale, with a higher number of participants who scored lower on pretest off-line participation, compared to the ones in the face-to-face condition (however, mean comparisons were insignificant). Since we would expect some sort of a ceiling effect for already engaged participants in Wave 1; participants in the web condition had hence more chances for an increase in participation. Thus controlling for pretest values renders the web condition insignificant. 


\section{References}

Bennett, L., Breunig, C., \& Givens, T. (2008). Communication and political mobilization: Digital media and the organization of anti-Iraq war demonstrations in the U.S. Political Communication, 25, 269-289.

Bennett, W. L. (2004). Communicating global activism. Strengths and vulnerabilities of networked politics. In: W. Van De Donk, B. Loader, P. Nixon, \& D. Rucht (Eds.), Cyberprotest. New media, citizens and social movements (pp. 109-128). London, England: Routledge.

Bennett, W. L. (2008). Changing citizenship in the digital age. In W. L. Bennett (Ed.), Civic life online. Learning how digital media can engage youth. (pp. 1-24). Cambridge, UK: MIT Press.

Best, S., \& Krueger, B. (2005). Analyzing the representativeness of Internet political participation. Political Behavior, 27, 183-216.

Bimber, B. (1998). The Internet and political mobilization—Research note on the 1996 election season. Social Science Computer Review, 16, 391-401.

Bimber, B. (2001). Information and political engagement in America: The search for effects of information technology at the individual level. Political Research Quarterly, 54, 53-67.

Bimber, B. (2003). Information and American democracy: Technology in the evolution of political power. Cambridge, UK: Cambridge University Press.

Brunsting, S., \& Postmes, T. (2002). Social movement participation in the digital age-predicting offline and online collective action. Small Group Research, 33, 525-554.

Cohen, J., Cohen, P., West, S. G., \& Aiken, L. S. (2003). Applied multiple regression/correlation analysis for the behavioral sciences. Mahwah, NJ: Lawrence Erlbaum.

Dale, A., \& Strauss, A. (2009). Don't forget to vote: Text message reminders as a mobilization tool. American Journal of Political Science, 53, 787-804.

De Vreese, C. H. (2007). Digital renaissance: Young consumer and citizen? Annals of the American Academy of Political and Social Science, 611, 207-216.

Diani, M. (2000). Social movement networks virtual and real. Information, Communication \& Society, 3, 386-401.

Di Gennaro, C., \& Dutton, W. (2006). The Internet and the public: Online and offline political participation in the United Kingdom. Parliamentary Affairs, 59, 299-313.

Earl, J. (2006). Pursuing social change online. The use of four protest tactics on the Internet. Social Science Computer Review, 24, 362-377.

Eurobarometer. (2008). Attitudes of European citizens towards the environment: Research report. Brussels, Belgium: European Commission. Retrieved October 25, 2010, from http://ec.europa.eu/public_opinion/ archives/ebs/ebs_295_en.pdf

Fisher, D., \& Boekkooi, M. (2010). Mobilizing friends and strangers. Information, Communication and Society, 13, 193-2008.

Gelman, A., \& Hill, J. (2007). Data analysis using regression and multilevel/ hierarchical models. Cambridge, UK: Cambridge University Press.

Gerber, A. S., \& Green, D. P. (2000). The effects of canvassing, telephone calls, and direct mail on voter turnout: A field experiment. American Political Science Review, 94, 653-663.

Gibson, R., \& Ward, S. (2009). Parties in the digital age. A review article. Representation, 45, 87-100.

Gibson, R. K., Lusoli, W., \& Ward, S. (2005). Online participation in the UK: Testing a 'contextualized' model of Internet effects. BJPIR, 7, 561-583.

Gosnell, H. F. (1927). Getting-out-to-vote: An experiment in the stimulation of voting. Chicago, IL: University of Chicago Press.

Green, D. P., \& Gerber, A. S. (2001, December 29). Getting out the youth vote: Results from randomized field experiments. Unpublished manuscript, Yale University, New Haven, CT, USA.

Hargittai, E. (2004). Classifying and coding online actions. Social Science Computer Review, 22, 210-227.

Hargittai, E., \& Hinnant, A. (2008). Digital inequality-Differences in young adults' use of the Internet. Communication Research, 35, 602-621. 
Herring, H. (2006). Energy efficiency-A critical view. Energy, 31, 10-20.

Hooghe, M., Quintelier, E., Claes, E., \& Dejaeghere, Y. (2009). Belgian Political Panel Survey (BPPS), 2006-2008. Leuven, Belgium: Centre for Political Research.

Hooghe, M., Stolle, D., Mahéo, V., \& Vissers, S. (2010). Why can’t a student be more like an average person? Sampling and attrition effects in social science field and laboratory experiments. Annals of the American Academy of Political and Social Science, 628, 85-96.

Jason, L. A., Rose, T., Ferrari, J. R., \& Barone, R. (1984). Personal versus impersonal methods for blood donations. Journal of Social Psychology, 123, 139-140.

Jennings, M. K., \& Zeitner, V. (2003). Internet use and civic engagement: A longitudinal analysis. Public Opinion Quarterly, 67, 311-334.

Johnson, T. J., \& Kaye, B. K. (2003). A boost or bust for democracy? How the web influences political attitudes and behaviors in the 1996 and 2000 presidential elections. The Harvard International Journal of Press/Politics, 8, 9-34.

Jowell, R. the Central Co-ordinating Team. (2005). European Social Survey 2004/2005: Technical report. London, UK: Centre for Comparative Social Surveys, City University.

Kam, C., Wilking, J., \& Zechmeister, E. (2007). Beyond the "Narrow Data Base": Another convenience sample for experimental research. Political Behavior, 29, 415-440.

Klandermans, B., \& Oegema, D. (1987). Potentials, networks, motivations, and barriers. Steps toward participation in social movements. American Sociological Review, 52, 519-531.

Kramer, G. H. (1970). Effects of precinct-level canvassing on voter behavior. Public Opinion Quarterly, 34, 560-572.

Kraut, R., Patterson, M., Lundmark, V., Kiesler, S., Mukopadhyay, T., \& Scherlis, W. (1998). Internet paradox-A social technology that reduces social involvement and psychological well-being? American Psychologist, 53, 1017-1031.

Krueger, B. S. (2002). Assessing the potential of Internet political participation in the United StatesA resource approach. American Politics Research, 30, 476-498.

Krueger, B. S. (2006). A comparison of conventional and Internet political mobilization. American Politics Research, 34, 759-776.

Laer, J. Van. (2010). Activists "online" and "offline": Internet as an information channel for protest demonstrations. Mobilization, 15, forthcoming.

Margolis, M., \& Resnick, D. (2000). Politics as usual: The cyberspace "revolution.". Thousand Oaks, CA: Sage.

Micheletti, M. (2003). Political virtue and shopping: Individuals, consumerism, and collective action. New York, NY: Palgrave MacMillan.

Miller, M. M., \& Reese, S. D. (1982). Media dependency as interaction. Effects of exposure and reliance on political activity and efficacy. Communication Research, 9, 227-248.

Mossberger, K., Tolbert, C. J., \& McNeal, R. S. (2008). Digital citizenship: The Internet, society, and participation. Cambridge, MA: MIT Press.

Mossberger, K., Tolbert, C. J., \& Stansbury, M. (2003). Virtual inequality. Beyond the digital divide. Washington, DC: Georgetown University Press.

Nickerson, D. W. (2007). The ineffectiveness of e-vites to democracy-Field experiments testing the role of e-mail on voter turnout. Social Science Computer Review, 25, 494-503.

Pearce, F. (1998). Consuming myths. New Scientist, 5, 18-19.

Prevost, A. K., \& Schaffner, B. (2008). Digital divide or just another absentee ballot? Evaluating Internet voting in the 2004 Michigan democratic primary. American Politics Research, 36, 510-529.

Quintelier, E., \& Vissers, S. (2008). The effect of Internet use on political participation an analysis of survey results for 16-year-olds in Belgium. Social Science Computer Review, 26, 411-427.

Rheingold, H. (2000). The virtual community: Homesteading on the electronic frontier. Boston, MA: MIT Press. 
Shah, D., Schmierbach, M., Hawkins, J., Espino, R., \& Donavan, J. (2002). Nonrecursive models of Internet use and community engagement: Questioning whether time spent online erodes social capital. Journalism \& Mass Communication Quarterly, 79, 964-998.

Tolbert, C. J., \& McNeal, R. S. (2003). Unraveling the effects of the Internet on political participation? Political Research Quarterly, 56, 175-185.

Uslaner, E. (2004). Trust, civic engagement and the Internet. Political Communication, 21, 223-242.

Van Aelst, P., \& Walgrave, S. (2002). New media, new movements? The role of the Internet in shaping the 'anti-globalization' movement. Information, Communication and Society, 5, 465-493.

Van Dijk, J. (2005). The deepening divide. London, England: Sage.

Verba, S., Schlozman, K. L., \& Brady, H. (1995). Voice and equality: Civic voluntarism in American Politics. Cambridge, UK: Harvard University Press.

Ward, S., \& Vedel, T. (2006). Introduction: The potential of the Internet revisited. Parliamentary Affairs, 59, 210-225.

Ward, S., Owen, D., Davis, R., \& Taras, D. (Eds.). (2008). Making a difference. A comparative view of the role of the Internet in election politics. Lanham, MD: Lexington Books.

Weber, L. M., Loumakis, A., \& Bergman, J. (2003). Who participates and why? An analysis of citizens on the Internet and the Mass Public. Social Science Computer Review, 21, 26-42.

\section{Bios}

Sara Vissers is a postdoctoral fellow at the Center for the Study of Democratic Citizenship, McGill University (Montréal, Canada). Her work focuses on the role of Internet for political participation and mobilization. e-mail: Sara.Vissers@mcgill.ca.

Marc Hooghe is a professor of Political Science at the University of Leuven (Belgium) and a visiting professor at the University of Lille-II (France). He holds a PhD in Political Science and in Sociology and he works mainly on political participation and social capital. e-mail: Marc.Hooghe@soc.kuleuven.be.

Dietlind Stolle is an associate professor of political science at McGill University and an affiliated researcher at the Department of Political Science at Stockholm University. Her research interests include the concepts of social capital, diversity, political participation, and political consumerism. e-mail: Dietlind.Stolle@mcgill.ca.

Valerie-Anne Mahéo is a doctoral student at the department of political science at McGill University. She is interested in and has published on youth political participation. e-mail: va.maheo@mail.mcgill.ca. 